\title{
Neurocognitive benchmarks following transplant for emerging cerebral adrenoleukodystrophy
}

Elizabeth I. Pierpont, PhD, David R. Nascene, MD, Ryan Shanley, MS, Daniel L. Kenney-Jung, MD, Richard S. Ziegler, PhD, Weston P. Miller, MD, Ashish O. Gupta, MD, Troy C. Lund, PhD, MD, Paul J. Orchard, MD, and Julie B. Eisengart, PhD

Neurology ${ }^{\circledR}$ 2020;95:e591-e600. doi:10.1212/WNL.0000000000009929
Correspondence

Dr. Pierpont

pier0053@umn.edu

\begin{abstract}
Objective

To quantify benchmark treatment outcomes that may be enabled by newborn screening surveillance for X-linked adrenoleukodystrophy (ALD), we report neurocognitive, neuropsychiatric, and MRI change for boys who underwent hematopoietic stem cell transplant (HSCT) at initial stages of demyelination, prior to neurocognitive signs of disease.
\end{abstract}

\section{Methods}

Retrospective chart review identified 36 patients whose cerebral ALD was detected and treated early, with lesion severity less than 5 on the ALD-specific MRI scoring system. Median age at transplant was 7.3 years (range, 4.0-16.1). Progression of radiologic disease on MRI in the 2 years following HSCT was examined relative to the severity of the initial lesion for 33 patients, and longitudinal neurocognitive and neuropsychiatric outcomes were studied for 30 patients.

\section{Results}

Patients whose pretransplant lesion extended beyond the splenium of the corpus callosum and adjacent periventricular white matter (MRI severity score $>2$ ) demonstrated lower posttransplant neurocognitive scores, more neuropsychiatric symptoms, and more disease progression on MRI than patients with a less severe lesion. Changes from baseline neurocognitive functioning were greater at 2 years posttransplant as compared to 1 year. There was greater variance and risk of lesion progression as pretransplant MRI severity increased.

\section{Conclusion}

To realize the full benefits of newborn screening, clinicians must detect very small demyelinating lesions during surveillance and intervene quickly. Novel interventions that reduce risks inherent in allogeneic transplantation are needed. Trial endpoints should include direct neurocognitive assessment and extend at least 2 years posttreatment to provide the greatest sensitivity to detect neurocognitive morbidity. 


\section{Glossary}

ALD = adrenoleukodystrophy; cALD = cerebral adrenoleukodystrophy; $C I=$ confidence interval; HSCT = hematopoietic stem cell transplantation; LS = low severity; $\mathbf{M C I D}$ = minimum clinically important difference; NBS = newborn screening; $\mathrm{TBI}=$ total body irradiation; VLS = very low severity.

The childhood cerebral form of X-linked adrenoleukodystrophy (ALD) is a fatal inflammatory demyelinating disease that emerges unpredictably in one-third of affected boys. ${ }^{1}$ Hematopoietic stem cell transplantation (HSCT) can halt the progression of cerebral ALD (cALD) if performed at an early stage, $^{2}$ although no current methodology can predict the onset or velocity of demyelination. ${ }^{3}$ Newborn screening (NBS) enables prospective monitoring to detect CALD at the earliest possible stage. ${ }^{4}$ Early intervention is critical, as longterm neurocognitive capabilities and other functional outcomes are associated with the severity of the MRI lesion and neurocognitive status at the time of $\mathrm{HSCT}^{2,5-7}$ Current understanding of outcomes is based largely on boys whose cALD was identified due to clinical signs, which may not emerge until the lesion has spread substantially. The NBS era requires that this understanding be updated.

We examined a cohort of patients whose lesions were detected early, approximating what may be found by NBS surveillance. ALD diagnosis occurred prior to cerebral involvement (e.g., by family history) in most cases. Based on the typical pattern of emergent demyelination in $\mathrm{CALD},{ }^{8}$ we hypothesized that when pretransplant lesions were restricted to the corpus callosum or immediately adjacent periventricular white matter, neurocognitive function 2 years after HSCT would be measurably better than for those with slightly more extensive lesions. Further, we hypothesized that posttransplant MRIs would show less progression for patients with milder initial lesions. Finally, our clinical observations suggested that neuropsychiatric concerns (e.g., inattention, behavior abnormalities) frequently arise, prompting measurement of neuropsychiatric symptomatology relative to initial lesion severity.

\section{Methods}

\section{Study population}

Brain MRIs for 149 consecutive patients with cALD who underwent allogeneic HSCT at the University of Minnesota between January 1, 1991, and April 30, 2017, were reviewed by a board-certified neuroradiologist (D.R.N.) who was blinded to the clinical status (e.g., neurocognitive and neuropsychiatric test scores) of the patients. The MRIs were scored using the Loes methodology ${ }^{9}(0=$ no cerebral involvement; 34 = maximal involvement of the considered regions). Thirty-six patients met the study inclusion criterion of a pretransplant MRI severity score between 0.5 and 4.5 , inclusive (figure 1). White matter lesions within this range of MRI severity are depicted in figure 2. Early identification of
cALD among this group of patients was possible due to family history of ALD $(n=28)$, workup following diagnosis of adrenal insufficiency $(n=6)$, or clinical symptoms prompting an MRI, i.e., severe migraine headaches $(n=1)$ or seizures $(\mathrm{n}=1)$.

\section{HSCT treatment protocols}

Patients received myeloablative transplant conditioning with either a busulfan-based regimen without radiation $(86 \%)$ or a high-dose total body irradiation (TBI)-based regimen (14\%; all prior to 2004). Allografts were from unrelated umbilical cord blood (33\%), bone marrow from related or unrelated donors (64\%), or peripheral blood stem cells from an unrelated donor (3\%). Immunosuppressive agents administered early in the transplant process included cyclosporine A, as well as mycophenolate mofetil, methotrexate, or corticosteroids, all used on a short-term basis. ${ }^{5,10}$ The cyclosporine was routinely tapered beginning 6 months after transplantation, with tapering of immunosuppression complete by 9 months posttransplantation.

\section{Neurocognitive and neuropsychiatric evaluation}

Test scores spanning 6 neurocognitive and 4 neuropsychiatric domains were obtained from pretransplant and posttransplant clinical neuropsychological evaluations (table 1). Verbal reasoning, visual reasoning, working memory, and processing speed, as well as fine motor dexterity and visualmotor abilities, were evaluated using methods previously described. ${ }^{11}$ Neuropsychiatric symptoms were measured with well-validated caregiver rating scales along domains of hyperactivity, attention problems, anxiety, and depression.

\section{Statistical analysis}

The first study objective was to analyze trends in outcomes by pretransplant MRI severity score. Using scatterplots, 2-year post-treatment neurocognitive and MRI outcomes were analyzed by pretransplant MRI severity score. To provide grouplevel statistics, patients were divided into 2 groups based on pretransplant MRI severity: very low severity (VLS; Loes score $=0.5-2.0)$ vs low severity (LS; Loes score 2.5-4.5), calculating the mean difference and its $95 \%$ confidence interval (CI) for each 2-year outcome.

The second objective was to study trends over time in each neurocognitive outcome, specifically to determine whether changes occur between 1 and 2 years post-transplant and to assess the magnitude of these changes relative to those occurring in the initial year after treatment. This analysis was designed to better delineate the timing of emerging 


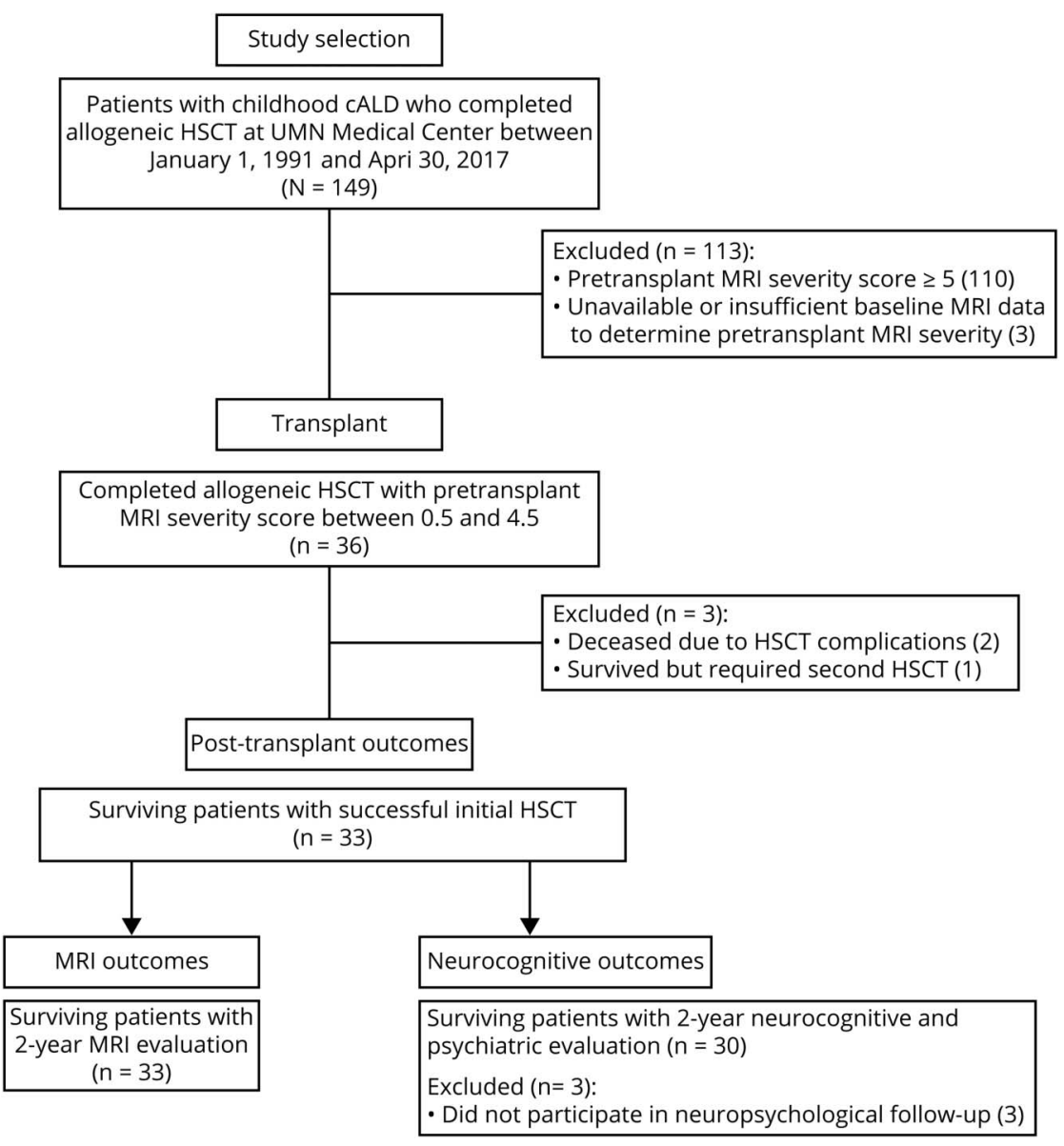

Of the 149 patients who underwent allogeneic
hematopoietic stem cell transplantation (HSCT), 36
had a pretransplant MRI severity score <5. In this
group, 33 patients survived and achieved accept-
able engraftment after a single HSCT. All 33 had
follow-up MRIs for analysis; 30 had neurocognitive
follow-up. CALD = cerebral adrenoleukodystrophy. post-transplant cognitive changes. Linear mixed models (i.e., repeated measures) included the neurocognitive test score as the outcome, predicted by pretransplant MRI severity score (modeled as a continuous variable) and years since HSCT (modeled categorically to allow for different effects for each year), and their interaction. Most patients had baseline and year 1 scores, and for each test, about 20 patients had available year 2 scores. The models included a random intercept and time effect for each patient. Results are reported as predicted values for an otherwise average patient with an MRI severity score of 1 , and likewise for a Loes score of 4 . This predictive model allowed utilization of all data points available to estimate neurocognitive trajectory within this time period. Analysis was conducted using the $\mathrm{R}$ lme4 package. $^{12}$

\section{Standard protocol approvals, registrations, and patient consents}

Ethics approval for this retrospective analysis was obtained from the University of Minnesota Institutional Review Board.

\section{Data availability}

Data supporting the findings of this study are available from the corresponding author upon reasonable request.

\section{Results}

\section{Sample characteristics, survival, and engraftment}

The majority of the cohort ( $31 / 36$ patients; $86 \%)$ demonstrated a predominately posterior radiographic presentation of cALD, with primary involvement of the splenium of the corpus callosum \pm parietal-occipital white matter. Two patients $(6 \%)$ had a frontal disease pattern with involvement of the genu and frontal white matter. Three patients (8\%) had atypical demyelination patterns: (1) posterior disease with involvement of genu; (2) frontal disease with involvement of brainstem; or (3) disease involving anterior temporal white matter and visual pathways.

HSCT for the 36 patients occurred at a median age of 7.3 years (range, 4.0-16.1). Two patients (pretransplant MRI severity scores of 2 and 4) experienced graft failure and a second transplant was performed; one of these patients survived and the other died of sepsis. One additional patient (pretransplant MRI severity score of 2) died due to transplant-related complications (sepsis, severe graft-versushost disease). Median 1- and 2-year engraftment was 100\%, and overall 2-year survival was $94 \%$ within the cohort. 
Figure 2 Progression of white matter disease in cerebral adrenoleukodystrophy
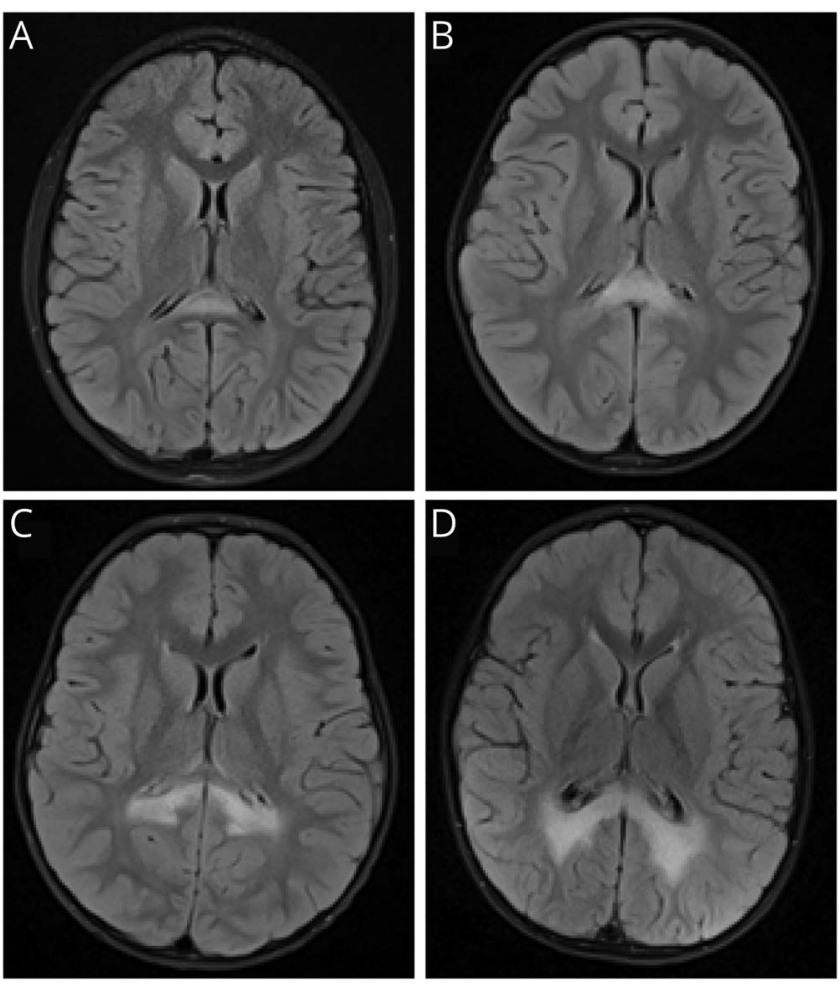

Representative T2 fluid-attenuated inversion recovery axial images demonstrate the differences in white matter involvement among MRI severity scores. In increasing order of lesion severity, images A-D depict MRI severity scores of $1,2,3$, and 4.5 respectively, as demyelination progresses further into the parietal white matter.

Outcomes of boys who died or received a second transplant were excluded, resulting in subsequent analysis of 33 patients (figure 1).

Among the 33 patients studied, 15 boys were in the VLS group and 18 boys were in the LS group. HSCT occurred at a similar age for patients in the VLS group (mean age, 7.8 years; SD, 2.3 years) as for patients in the LS group (mean age, 8.1 years; SD, 3.1 years; mean difference, -0.3 years; $95 \% \mathrm{CI}$, -2.3 to 1.6$)$. The proportion of boys receiving a TBI-based conditioning regimen was also similar for the VLS group (2/ 15 patients; $13 \%$ ) as for the LS group (3/18 patients; $17 \%$ ).

\section{MRI progression}

Figure 3 depicts post-transplant MRI disease progression as a function of pretreatment severity scores among the 33 patients scanned at baseline and 2 years post-transplant. There was greater variance and risk of disease progression as pretransplant MRI severity increased. Median post-transplant MRI progression for patients in the VLS group was 0 points on the Loes scale (range, 0-4). Median post-transplant MRI progression for patients in the LS group was 3.5 (range, 0-10).

\section{Neurocognitive and neuropsychiatric outcomes}

Neurocognitive test results were obtained from the closest time point preceding HSCT (median time before HSCT, 1.7 months; range, $0.3-5.3$ months) and the time point most proximal to 2 years post-transplant (median time since HSCT, 1.9 years; range, 1.0-3.0 years) for the 30 patients who returned for neurocognitive follow up. Table 2 presents results by pretransplant MRI severity (VLS vs LS). No group differences in pretransplant neurocognitive scores were observed. Two years after HSCT, the LS group performed worse than the VLS group on tests of processing speed and fine motor dexterity. Plotting pretransplant MRI severity score with 2-year outcomes illustrates that neurocognitive skills were differentially associated with lesion severity (figure 4).

In terms of neuropsychiatric findings, the LS group had more attention problems and symptoms of hyperactivity than the VLS group, both at baseline and at 2 years post-transplant. At the 2-year evaluation, 9/17 boys in the LS group (53\%) had ratings outside of normal limits ( $\mathrm{T}$ score $>60$ ) in at least one neuropsychiatric domain, as compared to $3 / 13$ boys in the VLS group (23\%). Neither group had mean neuropsychiatric scores in the clinically problematic range for any subscale.

\section{Longitudinal analysis}

Table 3 reports predicted longitudinal neurocognitive scores for average hypothetical patients with pretransplant MRI severity scores of 1 and 4, respectively. For patients with minimal disease (MRI severity 1), the model did not predict

Table 1 Neurocognitive and neuropsychiatric outcome measures

\begin{tabular}{|c|c|c|}
\hline Domains & Measures & Scores \\
\hline $\begin{array}{l}\text { Neurocognitive functioning } \\
\text { Verbal comprehension } \\
\text { Perceptual (visual) reasoning } \\
\text { Working memory } \\
\text { Processing speed } \\
\text { Fine motor dexterity } \\
\text { Visual-motor ability }\end{array}$ & $\begin{array}{l}\text { Wechsler scales, various editions: Wechsler Preschool and Primary Scale of } \\
\text { Intelligence; Wechsler Intelligence Scale for Children; Wechsler Adult } \\
\text { Intelligence Scale; Purdue Pegboard Test (3-trial average); Beery-Buktenica } \\
\text { Test of Visual-motor Integration, various editions }\end{array}$ & $\begin{array}{l}\text { Standard score, mean (SD) } 100 \text { (15) } \\
\text { higher scores indicate better } \\
\text { performance }\end{array}$ \\
\hline $\begin{array}{l}\text { Neuropsychiatric symptoms } \\
\text { Attention problems } \\
\text { Hyperactivity } \\
\text { Depression } \\
\text { Anxiety }\end{array}$ & $\begin{array}{l}\text { Behavior Assessment System for Children (various editions) or Personality } \\
\text { Inventory for Children }\end{array}$ & $\begin{array}{l}\text { T score, mean (SD) } 50(10) \text {, higher } \\
\text { scores indicate greater symptom } \\
\text { severity }\end{array}$ \\
\hline
\end{tabular}




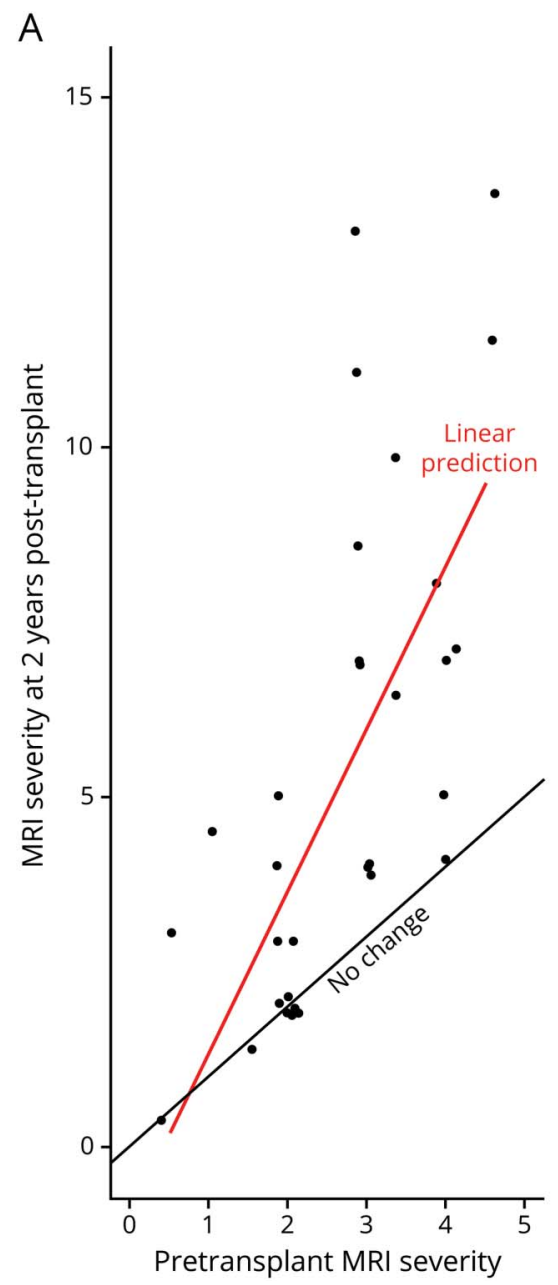

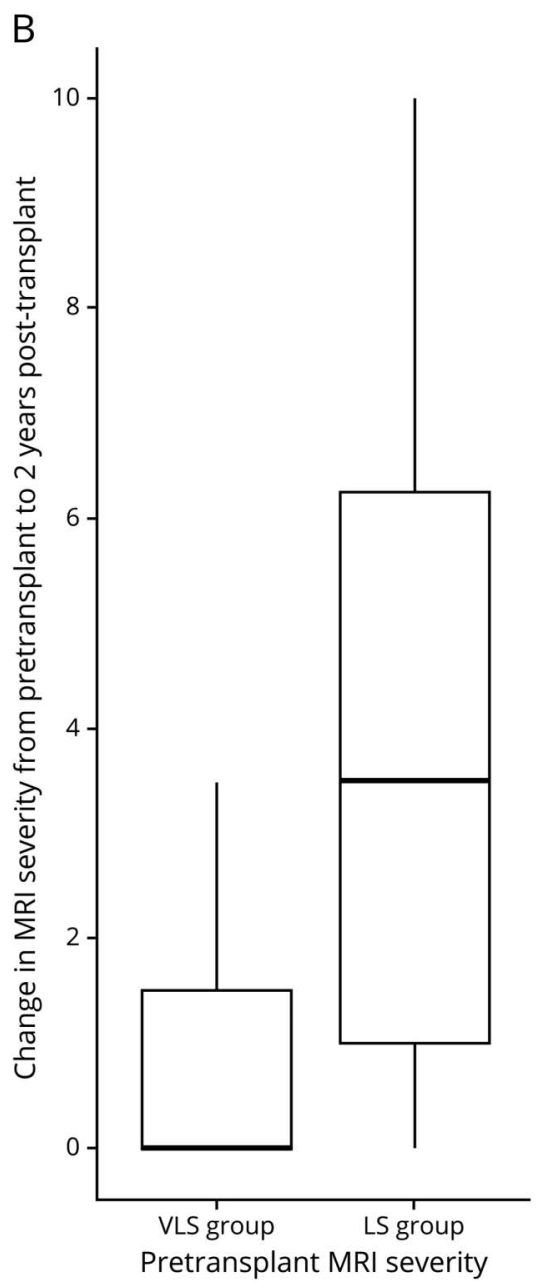

(A) Scatterplot of pretransplant MRI severity vs 2year MRI outcomes shows greater radiographic disease progression associated with higher pretransplant MRI score. The red line represents the regression line fitted to the data that were obtained. A black comparison line depicts the slope had there been no change in patient MRI scores from baseline to 2-years posttransplant. (B) Boxplots compare the change in MRI severity score from pretransplant to 2 years post-transplant in the very low severity (VLS) group (pretransplant MRI severity $0.5-2$ ) and the low severity (LS) group (pretransplant MRI severity 2.5-4.5). The lower and upper box boundaries correspond to the first and third quartiles (the 25th and 75th percentiles), with a black line at the median. For the VLS group, median change in MRI severity was 0 points; for the LS group, median change was 3.5 points. Vertical lines extend to the largest value no more than 1.5 times the interquartile range from the box boundary. consistent differences between baseline and 1- and 2-year scores. For patients with more extensive disease (MRI severity 4), the model predicted lower scores at 2 years as compared to 1 year for all neurocognitive measures. Thus, patients with higher pretransplant MRI severity scores were not only likely to have lower scores following transplantation, they were also more likely to show declines between 1 and 2 years post-transplant, especially for domains that were more vulnerable to cALD disease such as processing speed or fine motor dexterity.

\section{Discussion}

This investigation focused on a group of boys transplanted for cALD in the earliest stages of lesion development, in most cases before clinical signs of brain disease. Unlike most historical patient cohorts, familial diagnosis or other ALD symptoms (e.g., adrenal insufficiency) in these patients facilitated evaluation and monitoring prior to the development of a severe brain lesion. The cohort therefore offers insight into the cerebral involvement that may be detected during surveillance following a positive NBS. We present evidence that although disease-related neurocognitive symptoms are initially absent across the low range of the MRI severity scale, they emerge within a few years after transplantation. These findings have implications for realizing the promise of early detection through NBS: they imply that the window of watchful waiting between discovering a lesion and proceeding to transplant may be narrower than previously assumed, if neurocognitive and neuropsychiatric disease burden is to be avoided.

It is not known whether HSCT can prevent cerebral disease from emerging, but due to the inherent risk of transplantation, that study is unlikely to be conducted. The development of a gadolinium-enhancing lesion is considered evidence of active neuroinflammation and blood-brain barrier disruption, and has consistently been a clinical marker sufficient to justify moving forward with this intensive, risky therapy. ${ }^{13}$ Once white matter disease appears, a fairly predictable pattern of progression is observed. Demyelination typically begins in the splenium of the corpus callosum and spreads into parietal-occipital white matter 
Table 2 Neurocognitive and neuropsychiatric function of patients with early-stage cerebral adrenoleukodystrophy prior to and 2 years following hematopoietic stem cell transplantation

\begin{tabular}{|c|c|c|c|c|}
\hline & $\begin{array}{l}\text { Very low MRI severity } \\
\text { (Loes } 0.5-2 ; n=13) \text {, mean (SD) }\end{array}$ & $\begin{array}{l}\text { Low MRI severity } \\
\text { (Loes } 2.5-4.5 ; n=17 \text { ), mean (SD) }\end{array}$ & Mean difference & $95 \% \mathrm{Cl}$ \\
\hline \multicolumn{5}{|l|}{ 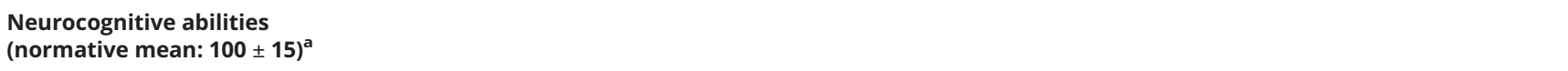 } \\
\hline \multicolumn{5}{|l|}{ Pretransplant } \\
\hline Verbal comprehension & $99.5(10.4)$ & $96.7(18.1)$ & -2.9 & -14.5 to 8.8 \\
\hline Visual reasoning & $103.8(17.1)$ & $99.4(11.7)$ & -4.4 & -15.1 to 6.4 \\
\hline Working memory & $90.2(12.1)$ & $94.5(16.6)$ & 4.3 & -8.4 to 17.0 \\
\hline Processing speed & $95.2(10.5)$ & $87.1(14.9)$ & -8.1 & -18.8 to 2.7 \\
\hline Fine motor dexterity & $92.8(14.5)$ & $88.4(15.1)$ & -4.4 & -15.9 to 7.0 \\
\hline Visual-motor integration & $90.5(12.2)$ & $92.9(10.8)$ & 2.4 & -6.4 to 11.4 \\
\hline \multicolumn{5}{|l|}{2 years post-transplant } \\
\hline Verbal comprehension & $96.3(11.0)$ & $97.0(22.9)$ & 0.7 & -14.1 to 15.4 \\
\hline Visual reasoning & $102.8(15.7)$ & $89.4(20.9)$ & -13.4 & -28.1 to 1.3 \\
\hline Working memory & $88.3(12.9)$ & $92.3(12.4)$ & 4.0 & -6.1 to 14.2 \\
\hline Processing speed & $95.7(15.4)$ & $77.9(15.6)^{c}$ & -17.7 & -29.9 to -5.5 \\
\hline Fine motor dexterity & $101.2(19.6)$ & $78.6(13.9)^{c}$ & -22.6 & -35.9 to -9.3 \\
\hline Visual-motor integration & $92.0(12.4)$ & $83.9(11.6)^{c}$ & -8.1 & -17.6 to 1.5 \\
\hline \multicolumn{5}{|l|}{ 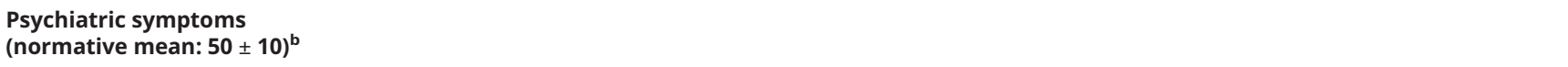 } \\
\hline \multicolumn{5}{|l|}{ Pretransplant } \\
\hline Hyperactivity & $47.3(12.7)$ & $58.1(16.8)$ & 10.8 & -0.9 to 22.5 \\
\hline Attention problems & $46.6(12.7)$ & $56.8(11.0)$ & 10.3 & 0.0 to 20.5 \\
\hline Depression & $49.8(13.7)$ & $51.7(13.3)$ & 1.9 & -8.6 to 12.4 \\
\hline Anxiety & $51.5(12.4)$ & $49.8(7.6)$ & -1.7 & -9.5 to 6.2 \\
\hline \multicolumn{5}{|l|}{2 years post-transplant } \\
\hline Hyperactivity & $47.1(14.9)$ & $57.1(17.4)$ & 9.9 & -2.5 to 22.4 \\
\hline Attention problems & $50.3(6.7)$ & $58.4(11.0)$ & 8.1 & 0.3 to 15.9 \\
\hline Depression & $49.2(7.9)$ & $54.2(9.7)$ & 5.0 & -1.9 to 11.8 \\
\hline Anxiety & $49.9(6.3)$ & $50.2(12.8)$ & 0.3 & -7.7 to 8.2 \\
\hline
\end{tabular}

Abbreviation: $\mathrm{Cl}=$ confidence interval.

${ }^{a}$ Higher scores indicate better neurocognitive test performance. Scores under 85 are below age expectations.

${ }^{\mathrm{b}}$ Higher scores indicate more psychopathologic symptomatology. Scores above 60 are outside normal limits.

${ }^{\mathrm{c}}$ Group mean scores outside of normal limits (>1 SD from normative mean).

( $80 \%$ of patients). Less commonly ( $\sim 20 \%$ of patients), the process begins in the anterior corpus callosum and extends into frontal regions, or presents in an atypical location such as the internal capsule. ${ }^{1}$ The current analysis suggests that as demyelination spreads beyond the corpus callosum and immediately adjacent periventricular white matter, risk heightens for further spreading of the lesion after treatment. Contrast enhancement on MRI, radiographic hypoperfusion, small volumetric lesion size at the initial scan, and young age of the patient are risk factors for more rapid progression. ${ }^{14-16}$ Complicating these circumstances is emerging evidence that initial changes on MRI can be missed during clinical interpretation. ${ }^{17}$ The subtle appearance of lesions with MRI severity <2 (figure 2) highlights the importance of meticulous MRI review by an experienced neuroradiologist so that very small changes are detected. When small lesions emerge at a young age, close follow-up with imaging and preparation to facilitate swift transplantation has been recommended. ${ }^{14,18}$ 
Figure 4 Two-year neurocognitive outcomes following hematopoietic stem cell transplantation at a stage of relatively low MRI severity
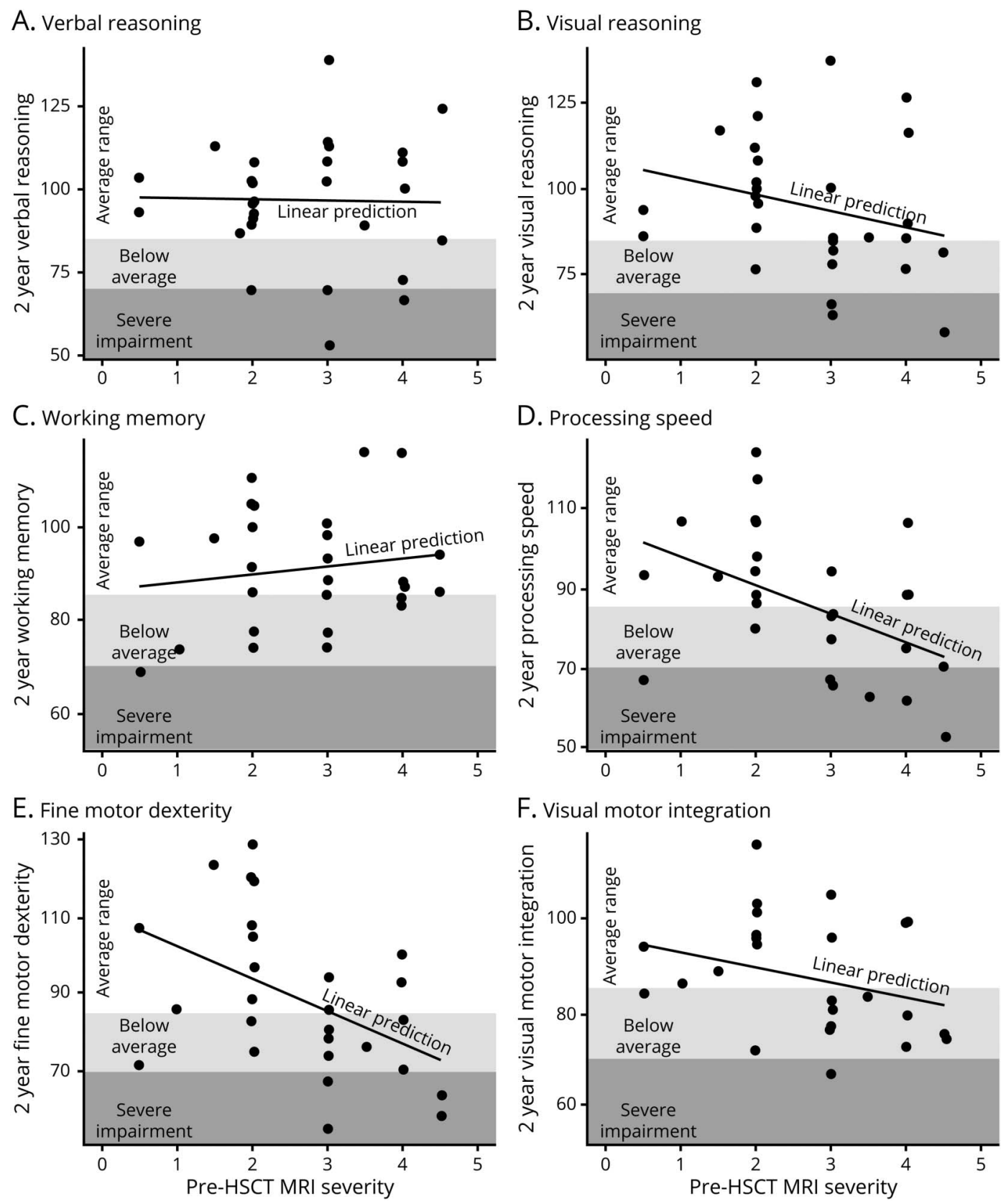

(A-F) The relationship of pretransplant MRI severity score plotted with 2-year transplant outcomes revealed that neurocognitive skill areas were differentially impacted. While domains such as processing speed and fine motor dexterity showed greater susceptibility to poor outcomes when the MRI severity was higher, verbal reasoning skills and working memory generally remained intact across this low severity spectrum. The resilience of verbal reasoning skills in particular can inflate the perception of a child's functioning, as a child with intact communication and motor coordination generally appears unaffected by disease, but these perceptions of intact functioning likely obscure cerebral adrenoleukodystrophy-related neurocognitive changes that can occur and were quantified in this study. HSCT = hematopoietic stem cell transplantation.

Findings from this study suggest that when lesions are small, the absence of directly quantified neurocognitive abnormalities is not a reason to delay transplant to continue monitoring by MRI. Specifically, transplantation upon first emergence of a T2 hyperintense lesion with gadolinium enhancement appears to be the most protective of functional outcomes. Across the spectrum of initially low severity lesions (i.e., MRI severity score $<5$ ), neurocognitive deficits were not detectable at the time of treatment by present standard neuropsychological measurement methodology. However, neurocognitive losses occurred in the years following HSCT for some patients, depending on lesion severity. At 2 years post-transplant, boys with the smallest pretransplant lesions (MRI severity score $0.5-2$ ) consistently performed within the age-expected range across a diverse array of neurocognitive tasks. In comparison, boys with slightly higher pretransplant MRI severity (2.5-4.5) 
Table 3 Regression model-based predicted neurocognitive scores over time as a function of pretransplant MRI severity

\begin{tabular}{llllllll}
\hline $\begin{array}{l}\text { Pre-HSCT MRI } \\
\text { severity }\end{array}$ & $\begin{array}{l}\text { Years since } \\
\text { transplant }\end{array}$ & $\begin{array}{l}\text { Verbal } \\
\text { reasoning }\end{array}$ & $\begin{array}{l}\text { Visual } \\
\text { reasoning }\end{array}$ & $\begin{array}{l}\text { Working } \\
\text { memory }\end{array}$ & $\begin{array}{l}\text { Processing } \\
\text { speed }\end{array}$ & $\begin{array}{l}\text { Fine motor } \\
\text { dexterity }\end{array}$ & $\begin{array}{l}\text { Visual motor } \\
\text { integration }\end{array}$ \\
\hline $\mathbf{1}$ & 0 & 107 & 111 & 94 & 99 & 93 & 94 \\
\hline $\mathbf{1}$ & 1 & 99 & 108 & 93 & 100 & 103 & 94 \\
\hline $\mathbf{1}$ & 2 & 103 & 105 & 87 & 95 & 106 & 95 \\
\hline $\mathbf{4}$ & 0 & 94 & 97 & 96 & 87 & 89 & 82 \\
\hline $\mathbf{4}$ & 1 & 98 & 90 & 98 & 86 & 75 & 82 \\
\hline $\mathbf{4}$ & 2 & 94 & 87 & 91 & 76 & 75 & 82 \\
\hline
\end{tabular}

Abbreviation: $\mathrm{HSCT}=$ hematopoietic stem cell transplantation.

This prediction table models the trend for an average hypothetical patient with pretransplant MRI severity of 1, and likewise for an average hypothetical patient with pretransplant MRI severity of 4 . Predicted scores were derived from repeated measures models that regress neurocognitive score on MRI severity, time, and their interaction. Approximately $80 \%-90 \%$ of actual scores were within 20 points of the model-predicted score.

performed below the age-expected range ( $>1$ SD below the normative mean) on post-transplant measures of processing speed, fine motor dexterity, and visual-motor integration. Verbal reasoning skills and working memory (short-term recall of information) remained generally stable across all patients, consistent with previous evidence that these functions can remain relatively intact even with advanced cALD. ${ }^{11}$ We speculate that differences in the observability of neurocognitive deficits, i.e., with some being obvious and others being less apparent, may be the reason that patients are sometimes described as asymptomatic across this spectrum of MRI severity and higher. ${ }^{14,19}$ Declines in visual perception or performancebased functions can be challenging to detect without repeated direct assessment. Neurocognitive testing appears to provide a much more sensitive assessment of deficiencies than neurologic or disability rating scores, or other surrogates from clinical chart review, which may not show sensitivity to functional changes until more advanced stages of cALD.

Our findings of deficits in processing speed, fine motor dexterity, and visual-motor integration have implications for learning, academic performance, and school engagement. These deficits may cause a student to struggle to keep up, avoid work, or feel inadequate. As they are invisible disabilities, they can cause affected students to appear unmotivated or noncompliant. Furthermore, the magnitude of changes observed in patients in the current study can be considered clinically meaningful. Standard methods for detecting a minimum clinically important difference (MCID) in neurocognitive scores and other quality of life assessments typically suggest that changes exceeding $0.5 \mathrm{SD}$ (i.e., 7.5 points for an IQ score) or 2 standard errors of measurement (SEM; typically around 3-6 points for index scores on the Wechsler scales) constitute a meaningful difference. ${ }^{20,21}$ Applying the criterion of $0.5 \mathrm{SD}$ for the MCID at the group level, observed declines from baseline to 2 years post-transplant could be considered clinically meaningful for the LS group in 4 neurocognitive domains: visual reasoning, processing speed, fine motor dexterity, and visual-motor integration. In contrast, no declines meeting this threshold were observed in the VLS group. Broadly speaking, preservation of a patient's full cognitive potential should be a key goal of successful treatment for neurologic disease, to maximize quality of life and independent functioning throughout the lifespan.

Another notable aspect of this study is the characterization of the neuropsychiatric status of our patients. Symptoms such as hyperactivity, attention problems, and mood/anxiety disturbance can hinder day-to-day functioning and warrant consideration in analyzing group-level post-treatment outcomes among boys with cALD. Certainly, receiving the diagnosis of a potentially fatal condition and confronting a high-risk intensive therapy creates stress that could manifest as emotional or behavioral challenges. Nevertheless, our analysis also indicates that caregiver-reported neuropsychiatric symptoms (in particular, problems with poor attention and hyperactive behaviors) are associated with the extent of the MRI lesion. This finding suggests increased mental health risk as cALD spreads, which can be underappreciated in this population and merits further prospective investigation.

The findings of the current study delineate key benchmark data against which to compare outcomes of novel interventions for cerebral disease in boys diagnosed with ALD by NBS. They also have implications for the timing of outcome evaluations employing neurocognitive endpoints. Among the domains most vulnerable to change (e.g., processing speed, fine motor dexterity), measurable declines were observed beyond 1 year post-transplant, especially for boys with greater-than-minimal disease at treatment. As such, we recommend that clinical research studies utilize a minimum trial length of 2 years following treatment, with consideration of extended follow-up, as deficits can become more pronounced over time. ${ }^{11,22}$ Further, it should be noted that clinical evaluation of neuropsychological function can be an important tool not only to collect trial endpoints, but also to provide educational recommendations and support families. 
The Loes MRI severity scoring system, while widely used in the field, may not be as sensitive to small changes as volumetric analysis. ${ }^{14}$ Since our patient cohort was limited to those with early cALD lesions, we did not distinguish among different cerebral patterns of disease; some research indicates that boys with posterior (parietal-occipital) pattern of disease have more favorable outcomes with higher MRI severity than patients with frontal pattern or other rare demyelination patterns. ${ }^{23}$ Patients with frontal disease pattern in our cohort may have skewed psychiatric outcomes (i.e., inattentive or hyperactive behaviors). However, the proportion of patients with frontal-predominant presentation was low $(6 \%)$. In order to study the impact of regional pattern on psychiatric outcomes more extensively, it would be ideal to compare patients with frontal pattern alongside patients with the classic posterior pattern who are matched for lesion severity or volume. Given the relative rarity of the frontal presentation, such an analysis may require a multicenter effort. As a final point, use of neurocognitive tools within this cohort depended on the ability to combine datasets across decades, which restricted the breadth and depth of neurocognitive domains examined.

Our data provide evidence that there are clear risks in not moving forward expeditiously toward a definitive intervention for patients with early-identified cerebral disease. A better understanding of the natural history of this disease before the lesion develops and more sensitive indicators of disease onset are needed to optimize surveillance methods. Identification and development of new, performance-based neurocognitive tests may hold promise for improved sensitivity to early-stage cALD or facilitate identification of deficits that coincide with or precede the development of a visible MRI lesion. Clinical trials of newer, safer therapies capable of minimizing disease progression would be of great benefit, not only in advanced disease, but also in those with emergent disease.

\section{Acknowledgment}

The authors thank the patients and their families; Erin McCoy, Julene Maniak, and Katherine Spurlock for research assistance; and Elsa Shapiro for original design of neuropsychological assessment methods, historical neurocognitive data acquisition, and consultation on this manuscript.

\section{Study funding}

This research was supported by the NIH's National Center for Advancing Translational Sciences, grants KL2TR002492 and UL1TR002494, and by the University of Minnesota Department of Pediatrics. The content is solely the responsibility of the authors and does not necessarily represent the official views of the NIH.

\section{Disclosure}

E. Pierpont reports no disclosures relevant to the manuscript. D. Nascene trains study reviewers in ALD scoring systems for WorldCare Clinical. R. Shanley, D. KenneyJung, and R. Ziegler report no disclosures relevant to the manuscript. W. Miller is a full-time employee of Sangamo Therapeutics. A. Gupta reports no disclosures relevant to the manuscript. T. Lund reports research support from bluebird bio. P. Orchard reports clinical trial support from bluebird bio and Magenta Therapeutics. J. Eisengart is an advisory board member for bluebird bio. Go to Neurology.org/ $\mathrm{N}$ for full disclosures.

\section{Publication history}

Received by Neurology October 18, 2019. Accepted in final form January 10, 2020.

Appendix Authors

\begin{tabular}{|c|c|c|}
\hline Name & Location & Contribution \\
\hline $\begin{array}{l}\text { Elizabeth } \\
\text { I. } \\
\text { Pierpont, } \\
\text { PhD }\end{array}$ & $\begin{array}{l}\text { Department of Pediatrics, } \\
\text { University of Minnesota, } \\
\text { Minneapolis }\end{array}$ & $\begin{array}{l}\text { Study concept and design, } \\
\text { data acquisition, analysis } \\
\text { and interpretation of data, } \\
\text { drafting/revising the } \\
\text { manuscript, accepts } \\
\text { responsibility for conduct of } \\
\text { research and final approval, } \\
\text { study supervision }\end{array}$ \\
\hline
\end{tabular}

\begin{tabular}{ll}
\hline David R. & Department of Radiology, \\
Nascene, & University of Minnesota, \\
MD & Minneapolis
\end{tabular}

MRI interpretation and scoring, revising the manuscript, accepts responsibility for conduct of research and final approval

\begin{tabular}{lll}
\hline Ryan & Bioinformatics and & Analysis and interpretation \\
Shanley, & Biostatistics Core, University & of data, drafting figures, \\
MS & of Minnesota, Minneapolis & $\begin{array}{l}\text { drafting/revising the } \\
\text { manuscript, accepts }\end{array}$ \\
& $\begin{array}{l}\text { responsibility for conduct of } \\
\text { research and final approval }\end{array}$
\end{tabular}

\begin{tabular}{lll}
\hline $\begin{array}{l}\text { Daniel } \\
\text { Kenney- } \\
\text { Jung, MD }\end{array}$ & $\begin{array}{l}\text { Department of Neurology, } \\
\text { University of Minnesota, } \\
\text { Minneapolis }\end{array}$ & $\begin{array}{l}\text { Drafting figures, revising the } \\
\text { manuscript, accepts } \\
\text { responsibility for conduct of } \\
\text { research and final approval }\end{array}$ \\
\hline $\begin{array}{l}\text { Richard S. } \\
\text { Ziegler, }\end{array}$ & $\begin{array}{l}\text { Department of Pediatrics, } \\
\text { University of Minnesota, } \\
\text { Minneapolis }\end{array}$ & $\begin{array}{l}\text { Acquisition of data, } \\
\text { interpretation of data, } \\
\text { revising the manuscript, } \\
\text { accepts responsibility for } \\
\text { conduct of research and } \\
\text { final approval }\end{array}$ \\
& &
\end{tabular}

\begin{tabular}{lll}
\hline $\begin{array}{l}\text { Weston P. } \\
\text { Miller, MD }\end{array}$ & $\begin{array}{l}\text { Department of Pediatrics, } \\
\text { University of Minnesota, } \\
\text { Minneapolis; Sangamo } \\
\text { Therapeutics, Richmond, CA }\end{array}$ & $\begin{array}{l}\text { Drafting/revising the } \\
\text { manuscript, interpretation } \\
\text { of data, accepts } \\
\text { responsibility for conduct of } \\
\text { research and final approval }\end{array}$ \\
\hline $\begin{array}{l}\text { Ashish O. } \\
\text { Gupta, MD }\end{array}$ & $\begin{array}{l}\text { Department of Pediatrics, } \\
\text { University of Minnesota, } \\
\text { Minneapolis }\end{array}$ & $\begin{array}{l}\text { Data acquisition, revising } \\
\text { the manuscript, } \\
\text { interpretation of data, } \\
\text { accepts responsibility for } \\
\text { conduct of research and } \\
\text { final approval }\end{array}$ \\
& &
\end{tabular}

\begin{tabular}{lll}
\hline $\begin{array}{l}\text { Troy C. } \\
\text { Lund, } \\
\text { PhD, MD }\end{array}$ & $\begin{array}{l}\text { Department of Pediatrics, } \\
\text { Minnersity of Minnesota, }\end{array}$ & $\begin{array}{l}\text { Data acquisition, revising } \\
\text { the manuscript, } \\
\text { interpretation of data, } \\
\text { accepts responsibility for } \\
\text { conduct of research and } \\
\text { final approval }\end{array}$ \\
\hline $\begin{array}{l}\text { Paul J. } \\
\text { Orchard, } \\
\text { MD }\end{array}$ & $\begin{array}{l}\text { Department of Pediatrics, } \\
\text { Minnersity of Minnesota, }\end{array}$ & $\begin{array}{l}\text { Revising the manuscript, } \\
\text { interpretation of data, } \\
\text { accepts responsibility for } \\
\text { conduct of research and } \\
\text { final approval }\end{array}$ \\
& &
\end{tabular}


Appendix (continued)

\begin{tabular}{lll}
\hline Name & Location & Contribution \\
\hline $\begin{array}{l}\text { Julie B. } \\
\text { Eisengart, }\end{array}$ & $\begin{array}{l}\text { Department of Pediatrics, } \\
\text { PhD }\end{array}$ & $\begin{array}{l}\text { Study concept and design, } \\
\text { data acquisition, analysis or } \\
\text { interpretation of data, } \\
\end{array}$ \\
& $\begin{array}{l}\text { drafting/revising the } \\
\text { manuscript, accepts } \\
\text { responsibility for conduct of } \\
\text { research and final approval, } \\
\text { study supervision }\end{array}$ \\
\end{tabular}

\section{References}

1. Moser HW, Mahmood A, Raymond GV. X-linked adrenoleukodystrophy. Nat Clin Pract Neurol 2007;3:140-151.

2. Peters C, Charnas LR, Tan Y, et al. Cerebral X-linked adrenoleukodystrophy: the international hematopoietic cell transplantation experience from 1982 to 1999. Blood 2004;104:881-888.

3. Engelen M, Kemp S, de Visser M, et al. X-linked adrenoleukodystrophy (X-ALD): clinical presentation and guidelines for diagnosis, follow-up and management. Orphanet J Rare Dis 2012;7:51.

4. Mallack EJ, Turk B, Yan H, Eichler FS. The landscape of hematopoietic stem cell transplant and gene therapy for X-linked adrenoleukodystrophy. Curr Treat Options Neurol 2019;21:61

5. Miller WP, Rothman SM, Nascene D, et al. Outcomes after allogeneic hematopoietic cell transplantation for childhood cerebral adrenoleukodystrophy: the largest singleinstitution cohort report. Blood 2011;118:1971-1978.

6. Pierpont EI, McCoy E, King KE, et al. Post-transplant adaptive function in childhood cerebral adrenoleukodystrophy. Ann Clin Transl Neurol 2018;5:252-261.

7. Raymond GV, Aubourg P, Paker A, et al. Survival and functional outcomes in boys with cerebral adrenoleukodystrophy with and without hematopoietic stem cell transplantation. Biol Blood Marrow Transpl 2019;25:538-548.

8. Loes DJ, Fatemi A, Melhem ER, et al. Analysis of MRI patterns aids prediction of progression in X-linked adrenoleukodystrophy. Neurology 2003;61:369-374.
9. Loes DJ, Hite S, Moser H, et al. Adrenoleukodystrophy: a scoring method for brain MR observations. AJNR Am J Neuroradiol 1994;15:1761-1766.

10. Gupta A, Downey M, Shanley R, et al. Reduced-toxicity (BuFlu) conditioning is better tolerated but has a higher second transplantation rate compared to myeloablative conditioning $(\mathrm{BuCy})$ in children with inherited metabolic disorders. Biol Blood Marrow Transpl 2020;26:488-492.

11. Pierpont EI, Eisengart JB, Shanley R, et al. Neurocognitive trajectory of boys who received a hematopoietic stem cell transplant at an early stage of childhood cerebral adrenoleukodystrophy. JAMA Neurol 2017;74:710-717.

12. Bates D, Maechler M, Bolker B, Walker S. Fitting linear mixed-effects models using lme4. J Stat Softw 2015;67:1-48.

13. Orchard PJ, Nascene DR, Miller WP, Gupta A, Kenney-Jung D, Lund TC. Successful donor engraftment and repair of the blood-brain barrier in cerebral adrenoleukodystrophy. Blood 2019;133:1378-1381.

14. Liberato AP, Mallack EJ, Aziz-Bose R, et al. MRI brain lesions in asymptomatic boys with X-linked adrenoleukodystrophy. Neurology 2019;92:e1698-e1708.

15. Melhem ER, Loes DJ, Georgiades CS, Raymond GV, Moser HW. X-linked adrenoleukodystrophy: the role of contrast-enhanced MR imaging in predicting disease progression. AJNR Am J Neuroradiol 2000;21:839-844.

16. Musolino PL, Rapalino O, Caruso P, Caviness VS, Eichler FS. Hypoperfusion predicts lesion progression in cerebral X-linked adrenoleukodystrophy. Brain 2012;135:2676-2683.

17. Swenson A, Nascene D. Early brain findings in cerebral adrenoleukodystrophy: are we missing subtle disease? American Society of Neuroradiology 57th annual meeting; May 21, 2019; Boston, MA.

18. Miller WP. Stem cell-transplantation therapy for adrenoleukodystrophy: current perspectives. J Neurorestoratology 2017;5:5-19.

19. Riva D, Bova SM, Bruzzone MG. Neuropsychological testing may predict early progression of asymptomatic adrenoleukodystrophy. Neurology 2000;54:1651-1655.

20. Norman GR, Sloan JA, Wyrwich KW. Interpretation of changes in health-related quality of life: the remarkable universality of half a standard deviation. Med Care 2003, 41:582-592.

21. Phillips R, Qi G, Collinson SL, et al. The minimum clinically important difference in the repeatable battery for the assessment of neuropsychological status. Clin Neuropsychol 2015;29:905-923.

22. Tran C, Patel J, Stacy H, et al. Long-term outcome of patients with X-linked adrenoleukodystrophy: a retrospective cohort study. Eur J Paediatr Neurol 2017;21:600-609.

23. Kühl JS, Kupper J, Baque H, et al. Potential risks to stable long-term outcome of allogeneic hematopoietic stem cell transplantation for children with cerebral X-linked adrenoleukodystrophy. JAMA Netw Open 2018;1:e180769. 


\section{Neurology}

\section{Neurocognitive benchmarks following transplant for emerging cerebral adrenoleukodystrophy \\ Elizabeth I. Pierpont, David R. Nascene, Ryan Shanley, et al. \\ Neurology 2020;95;e591-e600 Published Online before print July 2, 2020 \\ DOI 10.1212/WNL.0000000000009929}

This information is current as of July 2, 2020

\section{Updated Information \& Services}

\section{References}

Citations

Subspecialty Collections

Permissions \& Licensing

Reprints including high resolution figures, can be found at: http://n.neurology.org/content/95/5/e591.full

This article cites 22 articles, 8 of which you can access for free at: http://n.neurology.org/content/95/5/e591.full\#ref-list-1

This article has been cited by 3 HighWire-hosted articles: http://n.neurology.org/content/95/5/e591.full\#\#otherarticles

This article, along with others on similar topics, appears in the following collection(s):

All Demyelinating disease (CNS)

http://n.neurology.org/cgi/collection/all_demyelinating_disease_cns All Pediatric

http://n.neurology.org/cgi/collection/all_pediatric

Leukodystrophies

http://n.neurology.org/cgi/collection/leukodystrophies

MRI

http://n.neurology.org/cgi/collection/mri

Neuropsychological assessment

http://n.neurology.org/cgi/collection/neuropsychological_assessment

Information about reproducing this article in parts (figures,tables) or in its entirety can be found online at:

http://www.neurology.org/about/about_the_journal\#permissions

Information about ordering reprints can be found online:

http://n.neurology.org/subscribers/advertise

Neurology ${ }^{\circledR}$ is the official journal of the American Academy of Neurology. Published continuously since 1951, it is now a weekly with 48 issues per year. Copyright Copyright ( 2020 The Author(s). Published by Wolters Kluwer Health, Inc. on behalf of the American Academy of Neurology.. All rights reserved. Print ISSN: 0028-3878. Online ISSN: 1526-632X.

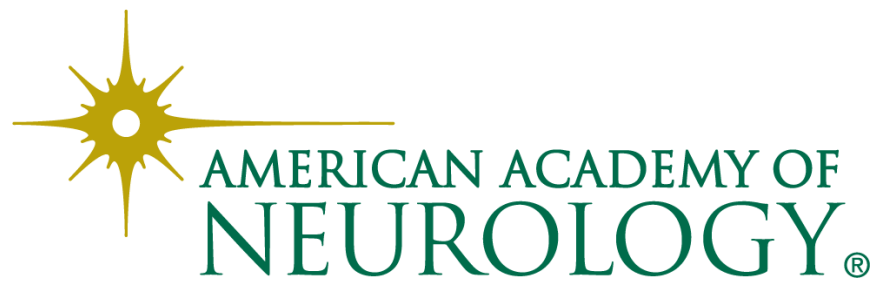

